\title{
EL INICIO DE UNA "RELACIÓN ESPECIAL" BALANCE HISTORIOGRÁFICO SOBRE LAS RELACIONES MÉXICO-JAPÓN DURANTE EL PORFIRIATO
}

\section{THE BEGINNING OF A "SPECIAL RELATIONSHIP" HISTORIOGRAPHICAL BALANCE OF MEXICO-JAPAN RELATIONS DURING THE PORFIRIATO}

\author{
JaCQues Coste CACHO \\ Instituto de Investigaciones Dr. José María Luis Mora, México \\ jacques.c.c@hotmail.com \\ https://doi.org/10.36105/iut.2021n33.09
}

Recibido: 02/08/2021

Aceptado: 30/08/2021

\section{RESUMEN}

Durante mi período como funcionario público en Cancillería, me llamaba la atención que, cada que preparábamos alguna reunión de los diplomáticos mexicanos con sus homólogos japoneses, los discursos que redactábamos contenían frases como: "Desde la formalización de los vínculos diplomáticos, México y Japón siempre han tenido una relación especial". Cuando elaboraba estos materiales, me preguntaba: ¿realmente la relación bilateral fue "especial" desde el principio? Y de ser así, ¿el carácter "especial” de esta relación está en sus orígenes o se forjó más adelante, conforme fueron evolucionando los vínculos entre ambos países? Estos cuestionamientos me impulsaron a hacer una revisión sobre lo que la academia mexicana ha escrito acerca de los inicios de la relación México-Japón. Aquí se presenta un balance historiográfico elaborado a partir de dicha revisión. 
Palabras clave:

Porfiriato, México, Japón, relaciones internacionales, diplomacia.

Abstract:

When I was a public servant at the Ministry of Foreign Affairs, it struck me that every time we prepared a meeting of Mexican diplomats with their Japanese counterparts, the speeches we wrote contained phrases such as: "Since the formalization of diplomatic ties, Mexico and Japan have always shared a special relationship". While preparing these materials, I used to ask myself: was the bilateral relationship really "special" from the beginning? And if so, where does the "special" nature comes from? These questions motivated me to review what Mexican scholars have written about the origins of the Mexico-Japan relationship. Hence, this article presents a historiographical balance elaborated from this review.

Keywords:

Porfiriato, Mexico, Japan, international relations, diplomacy.

\section{INTRODUCCIÓN}

Trabajé durante dos años en la Secretaría de Relaciones Exteriores de México, en donde me desempeñé como asesor para temas de la región Asia-Pacífico. Durante mi estancia en la Cancillería, siempre me llamó la atención que, cada que preparábamos alguna reunión de los entonces secretario y subsecretario de Relaciones Exteriores, Luis Videgaray y Carlos de Icaza, con sus homólogos japoneses, las tarjetas de apoyo y los discursos que redactábamos contenían frases como "Por nuestros lazos históricos, la relación de Japón y México va más allá de la diplomacia; es una relación de amistad fraterna" o "Desde la formalización de los vínculos diplomáticos, México y Japón siempre han tenido una relación especial".

Cuando elaboraba estos materiales, siempre pensaba que es indudable la importancia que la relación bilateral tiene para ambos países, pues Japón es uno de los principales socios comerciales, inversionistas extranjeros y aliados políticos de México. A la vez, nuestro país es de los pocos en el mundo que cuentan con un tratado de libre comercio con Japón. Sin embargo, más allá de eso, me preguntaba: ¿realmente la relación bilateral fue "especial" desde el principio?, ¿de verdad hay algo más allá de la importancia económica en esta alianza? y, de ser así, ¿el carácter "especial" de esta relación está en sus orígenes o se forjó más adelante conforme fueron evolucionando los vínculos entre ambos países?

Estos cuestionamientos me impulsaron a hacer una revisión sobre lo que la academia mexicana ha escrito acerca de los inicios de la relación México-Japón. Aquí se presenta un balance elaborado a partir de dicha revisión. En particular, se examinaron los textos que versan sobre las relaciones de México y Japón 
durante el porfiriato, período en el que se formalizaron los vínculos diplomáticos y se dieron los primeros contactos - económicos, migratorios, culturales y políticos- entre ambos países.

Vale la pena aclarar que sólo se revisó la literatura mexicana por dos motivos. En primer lugar, a pesar de que existen textos en inglés - escritos, principalmente, en universidades de Estados Unidos y Japón - que tratan el tema, mi interés radicaba en el carácter especial que México le brinda a la relación con Japón y no al revés. En segundo lugar, la barrera del idioma me impidió revisar la bibliografía japonesa.

Para cerrar este breve preámbulo, es importante precisar que, si bien las preguntas planteadas párrafos arriba son las que me motivaron a realizar este ejercicio, una vez iniciada la revisión historiográfica, consideré necesario añadir las siguientes preguntas para guiar mi lectura: ¿qué se ha escrito acerca de las relaciones diplomáticas México-Japón durante el porfiriato?, ¿desde qué perspectivas se ha tratado el tema?, ¿quiénes son las principales autoridades en la materia? y ¿qué consensos historiográficos hay sobre esta cuestión?

\section{TRATAMIENTOS DEL TEMA}

La producción historiográfica sobre la relación México-Japón durante el porfiriato es amplia sin llegar a ser muy vasta. Pese a que no existen demasiados escritos sobre el tema en particular, en muchos textos se toca tangencialmente la cuestión o, incluso, se le dedican apartados específicos. Por ejemplo, La política exterior del porfiriato de Roberta Lajous contiene amplios pasajes sobre la relación México-Japón. Asimismo, hay un apartado sobre la migración japonesa a México durante el porfiriato en Los extranjeros en México y los mexicanos en el extranjero de Moisés González Navarro.

En ese sentido, se pueden identificar cuatro enfoques principales tanto en la literatura que se centra específicamente en la relación México-Japón durante el porfiriato como en la que trata el tema como parte de un análisis más amplio. En primer lugar, varios autores han considerado que los procesos internos similares - la restauración Meiji en Japón y el porfiriato en México - propiciaron el acercamiento de ambos países. Estos estudios postulan que la modernización y la industrialización promovidas por el régimen porfirista mexicano y el gobierno imperial japonés hicieron posible el entendimiento entre este país latinoamericano y aquel archipiélago asiático.

En segundo lugar, hay varios textos que centran su atención en el Tratado de Amistad, Comercio y Navegación entre México y Japón de 1888. En general, describen el proceso de negociación que precedió a la firma del acuerdo, analizan la importancia que el pacto tuvo para ambas naciones y explican por qué su aplicación no trajo los beneficios económico-comerciales que se esperaban.

En tercer lugar, hay literatura que se concentra en la llegada de japoneses a México durante este período, la cual se dio por dos vías: la colonización y la inmigración de trabajadores contratados o "braceros". Por último, varios autores 
han escrito sobre cómo Estados Unidos influyó en la relación México-Japón en el contexto de la pugna por la hegemonía del Pacífico y las luchas imperialistas.

A continuación, en concordancia con esta división, se presentará un apartado dedicado a cada una de esas cuatro líneas de análisis. En esas secciones, se presentarán las ideas que los principales autores comparten en torno a cada subtema y se señalará si hay alguna interpretación que se desmarque de las visiones consensuadas. Posteriormente, se propondrán nuevas aristas desde las que se podría analizar la relación México-Japón durante el porfiriato con el objetivo de que otros investigadores puedan tratar el tema desde enfoques alternativos. Finalmente, con base en este balance, se presentarán algunas reflexiones alrededor de las preguntas planteadas en la introducción, particularmente, en torno al carácter "especial" de nuestros "lazos históricos" con Japón.

\section{LOS PROCESOS SIMILARES DE MODERNIZACIÓN MOTIVARON EL ACERCAMIENTO}

Varios autores que han escrito sobre la relación México-Japón durante el porfiriato han argumentado que el acercamiento de ambos países durante este período se relaciona con los procesos históricos similares que estaban viviendo. En Japón, después del shogunato, una etapa de dos siglos que se caracterizó por el aislacionismo y la organización política feudal, vino la restauración Meiji o, lo que es lo mismo, el restablecimiento del gobierno imperial, en la década de 1860. Este período estuvo marcado por una rápida modernización en todos los sectores: la industrialización económica, la abolición del orden feudal, la reforma al sistema de justicia con códigos y leyes al estilo occidental, la extensión de la educación pública y otros servicios básicos, el fortalecimiento del ejército, la construcción de redes ferroviarias, etc. No es necesario entrar mucho en detalles sobre el porfiriato, ya que es una etapa bien conocida de la historia nacional, pero vale la pena mencionar que México vivió un proceso parecido al japonés, pues el régimen de Díaz procuró que el país se montara en el carro de la modernidad mediante la estabilidad política y el crecimiento económico.

Para efectos de este trabajo, lo que importa no es desarrollar a fondo esta cuestión, sino dar cuenta de cómo los académicos han relacionado los procesos similares que México y Japón vivieron durante el porfiriato y la restauración Meiji con el establecimiento de las relaciones diplomáticas y el buen entendimiento entre ambos países. Por ejemplo, Francisco Javier Haro, José Luis León y Juan José Ramírez consideran que "La trayectoria de la relación fluida bilateral se explica no sólo por los sustanciales cambios en el sistema internacional, sino también por las trayectorias ascendentes de Japón y México en el último cuarto del siglo XIX. Por entonces, en efecto, ambos países experimentaban vigorosos procesos de modernización que exhibían múltiples semejanzas". ${ }^{1}$

Además, estos autores consideran que tanto México como Japón vivieron un proceso de industrialización tardía, lo cual influyó en el buen entendimiento

Haro, Francisco Javier; León, José Luis y RamíreZ, Juan José, “Japón y los contornos”, 2011, p. 117. 
de ambos países. Así, aunque este proceso se gestó a ritmos diferentes — pues el desarrollo nipón fue más rápido y avanzado que el mexicano-, ambos países tuvieron en común que la industrialización estuvo encabezada por regímenes autoritarios y eso también coadyuvó a que hubiera empatía entre los gobiernos. ${ }^{2}$

De acuerdo con Héctor Palacios, además del proceso de industrialización tardía, Japón y México compartían otras experiencias históricas similares como las recientes intervenciones de potencias extranjeras (por ejemplo, la incursión del comodoro estadounidense Christian Perry a Japón en la década de 1850 o la intervención francesa por la que se instauró el Segundo Imperio en México en la década de 1860), que habían mermado la soberanía de ambos países. Así, el autor considera que "el paralelismo cronológico cuenta para esta narración [sobre el inicio de las relaciones México-Japón]". ${ }^{3}$

Llama la atención que Palacios considere que las experiencias históricas de ambos países no sólo eran similares, sino paralelas, lo que hace que el autor exponga una narrativa teleológica sobre el origen de la relación bilateral, como se muestra en la siguiente afirmación: "En 1876, en México, mediante las armas se instauró un gobierno fuerte encabezado por Porfirio Díaz, el cual consolidaría la creación de dicho Estado-nación moderno. En 1877, en Japón, se afianzó definitivamente el proyecto modernizador al derrotar militarmente a la oposición samurai encabezada por el respetable líder Saigō Takamori. Ambas naciones estaban cerca de encontrarse políticamente una con otra". ${ }^{4}$

Otros autores no llegan al grado de considerar que los procesos contemporáneos de modernización hicieron del acercamiento entre ambas naciones algo inevitable, pero sí les otorgan importancia a estos procesos como un factor que contribuyó al buen entendimiento entre los dos gobiernos. En sus respectivos escritos, Enrique Cortés, Roberta Lajous, Carlos Almada, María Elena Ota Mishima, Iyo Kunimoto y Moisés González Navarro dan cuenta de esta interpretación más matizada. ${ }^{5}$

En ese sentido, varios autores arguyen que los procesos de modernización no sólo facilitaron el entendimiento entre los dos gobiernos, sino que contribuyeron a la buena imagen que los mexicanos tenían sobre los japoneses. Puesto que Japón se había modernizado a un ritmo increíblemente rápido, el régimen porfirista veía a los nipones como ejemplo a seguir. Además, la prensa, la élite económica y los intelectuales de México también observaban con admiración la industrialización y el reformismo de Japón. Esto hizo crecer el interés mexicano en traer colonos y productos japoneses al país. ${ }^{6}$ Enrique Cortés plantea que, considerando los bajos niveles de inmigración, comercio e inversión de ese país en el

Ibidem, pp. 117-134.

3 Palacios, Héctor, “Japón y México”, 2012, p. 115.

4 Ibidem, p. 116.

5 Contés, Enrique, Relaciones entre México, 1980; LAJous, Roberta, La política exterior, 2010; ALmADA, Carlos, México y Japón, 2018; Ota Mishima, María Elena, México y Japón, 1976; Kunimoto, Iyo, “La negociación del Tratado", 2008; y González Navarro, Moisés, Los extranjeros en México, vol. 2, 1994.

6 Almada, Carlos, México y Japón, 2018, pp. 27-68; Lajous, Roberta, La política exterior, 2010, pp. 109-145; y CORTÉs, Enrique, Relaciones entre México, 1980, pp. 103-121. 
nuestro, el interés de la élite mexicana en lo japonés es destacado, pues demuestra la afinidad cultural entre ambos pueblos y las aspiraciones similares de ambas naciones. $^{7}$

Iyo Kunimoto y Héctor Palacios esgrimen otro argumento sobre cómo influyeron los procesos históricos similares en la buena relación de ambos países: las experiencias internacionales traumáticas, como las intervenciones militares y la negociación de acuerdos desfavorables con potencias extranjeras, hacían propicio el entendimiento mutuo. Además, según estos autores, el entendimiento era aún más factible si se toma en cuenta que ambos gobiernos tenían interés en que sus países entraran de lleno en el concierto de las naciones y se sentaran en la misma mesa que los Estados civilizados. ${ }^{8}$

Finalmente, Moisés González Navarro expone una hipótesis interesante sobre por qué estas experiencias históricas similares dieron resultados tan distintos en ambos países. El autor considera que, pese a las similitudes entre la restauración Meiji y el porfiriato, los procesos de ambos países difieren por la insularidad y la homogeneidad cultural de Japón en contaste con la cercanía de México a EUA y la heterogeneidad cultural de nuestro país. Adicionalmente, "la burguesía japonesa fue capaz de transformar su país sin desintegrarlo culturalmente; la burguesía mexicana no pudo hacerlo por ser vicaria de la norteamericana y la europea". 9 Aunque el autor no profundiza en esta idea, no deja de ser un planteamiento interesante y digno de desarrollarse más ampliamente en futuras investigaciones.

\section{EL TRATADO DE 1888}

Quizá el aspecto que más se ha trabajado de la relación México-Japón durante el porfiriato sea el Tratado de Amistad, Comercio y Navegación entre México y Japón. Las tres aristas desde donde se trata este subtema son: 1) la descripción de las negociaciones que condujeron a la firma del acuerdo, 2) las razones por las que ambos países firmaron el pacto y 3) los efectos y la importancia del tratado.

En cuanto a las conversaciones previas a la suscripción del acuerdo, dos textos imprescindibles son México y Japón: a 130 años de relaciones diplomáticas de Carlos Almada y "La negociación del Tratado de Amistad, Comercio y Navegación de 1888 y su significado histórico" de Iyo Kumimoto. Sin embargo, muchos otros escritos narran este proceso de manera más sucinta. Entre ellos, destacan Relaciones entre México y Japón durante el porfiriato de Enrique Cortés y "Japón y México: el inicio de sus relaciones y la inmigración japonesa durante el Porfiriato" de Héctor Palacios.

Almada considera que las negociaciones del tratado se podrían dividir en tres fases: una etapa inicial de acercamiento, un prolongado estancamiento y un

7 CORTÉs, Enrique, Relaciones entre México, 1980, pp. 103-121.

8 Palacios, Héctor, "Japón y México", 2012, pp. 105-140 y Kunimoto, Iyo, "La negociación del Tratado", 2008, pp. 91-100.

9 González Navarro, Moisés, Los extranjeros en México, 1994, vol. 2, p. 185. 
rápido avance final. El primer acercamiento se dio en 1882, en la capital estadounidense, por medio de Matías Romero, ministro de México en Washington, quien le comunicó a su homólogo japonés el interés mexicano en establecer vínculos diplomáticos con su país. El delegado nipón respondió que, en ese momento, su gobierno no estaba listo para formalizar relaciones con ningún país occidental, pues su prioridad era renegociar los tratados que había acordado en condiciones desfavorables con las potencias europeas a mediados de siglo. Esa negativa dio inicio a un período de estancamiento que duró aproximadamente seis años, hasta que Japón se dijo listo para iniciar las negociaciones de un tratado de amistad con México, las cuales, concluyeron en noviembre de $1888 .{ }^{10}$

Iyo Kunimoto también realiza una narración muy precisa sobre las conversaciones previas al tratado. El autor destaca la labor de Matías Romero y Munemitsu Mutsu, quienes encabezaban las delegaciones diplomáticas de sus países en Estados Unidos. Ambos fueron hábiles negociadores y conjuntaron esfuerzos para que el tratado pudiera concretarse lo más pronto posible. Inclusive, fueron ellos quienes firmaron el documento final. ${ }^{11}$

En ese sentido, cabe subrayar que varios autores coinciden en resaltar la habilidad de Matías Romero como uno de los factores fundamentales para agilizar el proceso de negociación. Un ejemplo que estos investigadores establecen para ilustrar las aptitudes de Romero es que, antes de firmar el Tratado, el ministro mexicano se reunió con funcionarios estadounidenses para verificar que su gobierno no viera con malos ojos el acuerdo y, así, evitar problemas con la Unión Americana. ${ }^{12}$ Roberta Lajous no sólo se detiene en la figura de Romero, sino que también hace un juicio positivo sobre Ignacio Mariscal — quien, en esa época, encabezaba la Cancillería mexicana - por su estrategia de diversificación de los vínculos con el exterior, dentro de la cual se consideraba el establecimiento de lazos con Japón. ${ }^{13}$

Pero ¿por qué seis años después de haber rechazado la oferta mexicana, Japón modificó su postura y manifestó estar listo para firmar un tratado? La respuesta más común es que Japón cambió su posición debido a que necesitaba un precedente para poder renegociar los tratados desiguales que había firmado con las potencias occidentales a mediados de siglo. ${ }^{14}$

El gobierno nipón concebía los tratados firmados a mitad de siglo como un ataque a su soberanía nacional, ya que éstos se suscribieron en un momento de

10 Almada, Carlos, México y Japón, 2018, pp. 27-68.

11 Kunimoto, Iyo, "La negociación del Tratado", 2008, pp. 91-100.

12 Los siguientes textos coinciden tanto en los elogios a Romero como en el ejemplo sobre su pericia: ALMADA, Carlos, México y Japón, 2018, pp. 27-68; Kunimoto, Iyo, "La negociación del Tratado", 2008, pp. 91-100; CORTÉs, Enrique, Relaciones entre México, 1980, pp. 32-51; LAJous, Roberta, La política exterior, 2010, pp. 139-145; y Palacios, Héctor, “Japón y México", 2012, pp. 105-140.

14 En esta explicación coinciden los siguientes estudios: Almada, Carlos, México y Japón, 2018, pp. 27-68; Kunimoto, Iyo, "La negociación del Tratado", 2008; Haro, Francisco Javier; León, José Luis y Ramírez, Juan José, “Japón y los contornos”, 2011, pp. 117-134. y PALACios, Héctor, “Japón y México”, 2012, pp. 105-140. 
debilidad — el paso del shogunato a la restauración Meiji_, que las potencias occidentales aprovecharon para imponer condiciones inequitativas. Los acuerdos no reconocían la jurisdicción de los tribunales japoneses sobre los ciudadanos de países occidentales, además de que le imponían a Japón la obligación de importar los bienes provenientes de esas naciones con cuotas arancelarias bajas, lo cual mermaba los ingresos fiscales del Imperio. Para colmo, preveían que Japón debía darle el trato de nación más favorecida a todos los países con los que había firmado tratados, entre los que se encontraban Estados Unidos, Gran Bretaña y Rusia. ${ }^{15}$

Japón había intentado dialogar colectivamente con los países europeos y Estados Unidos la derogación de los viejos tratados y el establecimiento de nuevos acuerdos sobre bases igualitarias, pero esta estrategia resultó fallida. Al conde Okuma, quien encabezó la Cancillería japonesa en la década de 1880, se le ocurrió que sería mejor negociar con algún país occidental un tratado igualitario $\mathrm{y}$, después, utilizar ese pacto como precedente para establecer las mismas condiciones en sus relaciones con los demás Estados de Occidente. México resultó ser un buen candidato, puesto que su gobierno ya había manifestado interés en acercarse a Japón. Además, tomando en cuenta la distancia entre ambos países y las condiciones económicas mexicanas, sería difícil que un tratado incentivara la llegada de grandes flujos de migrantes al archipiélago. ${ }^{16}$

Ahora bien, los autores esgrimen distintos argumentos para explicar por qué la parte mexicana decidió firmar el pacto y no dudó en responder positivamente a la solicitud japonesa. Enrique Cortés considera que el interés en exportar plata directamente al país asiático fue un factor fundamental para esta decisión. Los minerales mexicanos se enviaban a Asia a través de intermediarios - en su mayoría, comerciantes británicos-, lo cual reducía los beneficios de esta actividad económica para México, por lo que el régimen porfirista deseaba poder comerciar directamente estos metales preciosos en Oriente. ${ }^{17}$

Por su parte, autores como Roberta Lajous, Gabriela Rodríguez Huerta, Bertha Ulloa y Carlos Almada coinciden en cuanto a que el acercamiento de México hacia Japón respondió a uno de los objetivos principales de la política exterior porfirista: diversificar los vínculos en el extranjero con el fin de reducir la influencia política de Estados Unidos en los asuntos internos y la dependencia económica hacia Washington. ${ }^{18}$ Finalmente, autores como Moisés González Navarro, José Luis León Manríquez y María Elena Ota Mishima mencionan el interés de Díaz en traer colonos japonesas para poblar las zonas mexicanas deshabitadas y explotar los recursos de esas mismas regiones como un motivo importante por el cual México firmó el tratado. ${ }^{19}$

15 Idem

16 Idem

17 ContÉs, Enrique, Relaciones entre México, 1980, pp. 32-51.

18 Lajous, Roberta, "El porfiriato", 2012, pp. 116-143; Lajous, Roberta, La política exterior, 2010, pp. 19-20; Almada, Carlos, México y Japón, 2018, pp. 27-68; UlloA, Bertha, "El juego de las potencias", 2010, pp. 51-66 y RodríGuez HuerTa, Gabriela, "Recorrido histórico", 2017, pp. 87-104.

19 GonzÁlez Navarro, Moisés, Los extranjeros en México, 1994, vol. 2, pp. 163-185; Ota Mishima, María Elena, "Características sociales", 1997, pp. 55-84; y León MANRíQuez, José Luis y Tizili Apango, Eduardo, "México y Asia", 2015, pp. 113-139. 
Por último, en cuanto a los efectos y la importancia del tratado, hay distintas interpretaciones. A grandes rasgos, los autores consideran que las consecuencias materiales y económicas del pacto fueron magras, pero, aun así, el acuerdo tuvo un valor simbólico y diplomático apreciable. Para México, su importancia radicaba en que se trata del documento que oficializó los vínculos con el primer país asiático con el que estableció relaciones diplomáticas en la historia. Para Japón, el acuerdo era relevante debido a que fue la primera ocasión en que un Estado occidental lo reconoció como igual, además de que su firma sentó un precedente que Japón pudo utilizar en la renegociación de los tratados desfavorables que tenía con las naciones europeas y EUA ${ }^{20}$ Iyo Kunimoto va más allá, pues considera que "El Tratado concluido con México dio comienzo a una nueva época en la historia diplomática del Japón moderno". ${ }^{21}$

En ese sentido, varios autores coinciden en la idea de que los dos artículos más importantes del tratado fueron el cuarto y el octavo. El artículo IV otorgaba la libertad de tránsito por todo el territorio japonés a los mexicanos que viajaran o residieran en ese país. El artículo VIII preveía que los mexicanos presentes en Japón debían someterse a las leyes nacionales y reconocer la jurisdicción de los tribunales nipones. Japón tomó estas dos cláusulas como precedente para las futuras negociaciones con Occidente: a cambio de otorgar la libertad de tránsito y comercio a los ciudadanos europeos y estadounidenses, que anteriormente debían restringir su presencia a las provincias costeras, el Imperio podría exigir el reconocimiento de la competencia de sus juzgados. ${ }^{22}$

De acuerdo con Carlos Almada, el tratado no rindió los frutos esperados en materia de comercio e inversión debido a tres motivos: la pérdida de importancia de la plata en los mercados internacionales, la ausencia de rutas marítimas directas entre ambos países y la escasa complementariedad económica. ${ }^{23}$ Enrique Cortés arguye que los magros resultados se debieron a que las exportaciones mexicanas eran poco atractivas para Japón, pues la plata había perdido importancia y le resultaba menos costoso y más fácil importar productos agrícolas de sus vecinos del sudeste asiático. Además, Japón consideraba que México estaba en la esfera de influencia estadounidense y quería evitar problemas con esa nación. ${ }^{24}$

Más allá de ello, los autores coinciden en que la importancia práctica del tratado radica en que abrió un período de diálogo y amistad entre Japón y México, países que se caracterizaron por tener una relación cordial de respeto mutuo

20 Los siguientes estudios coinciden en esta interpretación: CoRTÉs, Enrique, Relaciones entre México, 1980, pp. 32-51; Lajous, Roberta, La política exterior, 2010, pp. 19-20; Aranda Ávila, Joel, "Revisión histórica", 2012, pp. 59-78; Palacios, Héctor, "Japón y México", 2012, pp. 105-140; Ota Mishima, María Elena, México y Japón, 1976; León Manríquez, José Luis y Tizili Apango, Eduardo, "México y Asia”, 2015, pp. 113-139; у Kunimoto, Iyo, "La negociación del Tratado", 2008.

21 Kunimoto, Iyo, "La negociación del Tratado", 2008, p. 99.

22 Cortés, Enrique, Relaciones entre México, 1980, pp. 32-51; Almada, Carlos, México y Japón, 2018, pp. 27-68; Кunimoto, Iyo, "La negociación del Tratado", 2008, pp. 91-100; PalaCios, Héctor, "Japón y México", 2012, pp. 105-140; y Haro, Francisco Javier; León, José Luis y RamíreZ, Juan José, “Japón y los contornos”, 2011, p. 119.

23 Almada, Carlos, México y Japón, 2018, pp. 27-68.

24 CORTÉs, Enrique, Relaciones entre México, 1980, p. 63. 
y de gran afinidad cultural. ${ }^{25}$ Para ilustrar esa cercanía política, los estudiosos extienden los siguientes ejemplos: la ubicación y la majestuosidad del edificio que el gobierno japonés destinó a la embajada mexicana como muestra de gratitud por ser la primera nación occidental con la que estableció una relación equitativa; ${ }^{26}$ el trato especial que Porfirio Díaz otorgó a la delegación nipona que acudió a los festejos del centenario de la independencia; ${ }^{27}$ la instalación de la Exposición Japonesa durante esos festejos, la cual inauguró el presidente mexicano y fue la única exhibición internacional que se presentó en el centenario, ${ }^{28}$ y el nombramiento de Porfirio Díaz hijo como embajador de México en Japón, que, aunque no se pudo concretar por el estallido de la Revolución, fue una muestra de la buena relación bilateral y de la importancia que el presidente mexicano le otorgaba al Imperio nipón. ${ }^{29}$

\section{COLONIZACIÓN Y MIGRACIÓN}

Muchos de los textos que se han citado hasta el momento analizan los flujos migratorios de japoneses que el México porfirista recibió. Existen varios consensos respecto a este tema en la mayoría de la literatura. Sin embargo, hay tres autores que se han especializado en el tema de la migración, por lo que abordan esta cuestión de manera más completa y precisa que los demás: María Elena Ota Mishima, Héctor Palacios y Moisés González Navarro. Por esos motivos, primero, se expondrán las reflexiones que comparten la mayoría de los autores y, después, se dedicarán algunos párrafos a la obra de los tres académicos más especializados.

Varios estudiosos coinciden en apuntar que las necesidades poblacionales de ambos países eran complementarias: México estaba subpoblado y necesitaba mano de obra para explotar las tierras de las regiones despobladas, mientras que la población japonesa crecía a un ritmo vertiginoso, lo que hizo que el Estado impulsara la emigración para evitar la sobrepoblación. Además, en nuestro país se veía con admiración la laboriosa cultura nipona, por lo que se consideraba que los inmigrantes de esa nación serían eficientes para trabajar el campo de las zonas inhabitadas y para colaborar en la extensión de las vías férreas. ${ }^{30}$

25 Lajous, Roberta, "El porfiriato", 2012, pp. 116-143; LAJous, Roberta, La política exterior, 2010, pp. 19-20; Almada, Carlos, México y Japón, 2018, pp. 27-68; Cortés, Enrique, Relaciones entre México, 1980, pp. 103-121.

26 Lajous, Roberta, La política exterior, 2010, p. 111; Haro, Francisco Javier; LeÓn, José Luis y RAMírez, Juan José, “Japón y los contornos", 2011, p. 120 y Almada, México y Japón, 2018, pp. 27-68.

27 Almada, Carlos, México y Japón, 2018, pp. 27-68 y CoRTés, Enrique, Relaciones entre México, 1980, pp. 103-121.

28 Lajous, Roberta, La política exterior, 2010, p. 142; Almada, Carlos, México y Japón, 2018, pp. 27-68 y CORTÉs, Enrique, Relaciones entre México, 1980, pp. 103-121.

29 Lajous, Roberta, La política exterior, 2010, p. 144; Almada, Carlos, México y Japón, 2018, pp. 27-68 y CORTÉs, Enrique, Relaciones entre México, 1980, pp. 103-121.

30 Cortés, Enrique, Relaciones entre México, 1980, pp. 70-103; Lajous, Roberta, La política exterior, 2010, pp. 109-145; León Manríluez, José Luis y Tizili Apango, Eduardo, "México y Asia", 2015, pp. 113-139; Kunimoto, Iyo, “La negociación del Tratado", 2008, pp. 91-100; y AlmadA, Carlos, México y Japón, 2018, pp. 27-68. 
Esos mismos autores consideran que todo esto contribuyó a que el sector público y el empresariado de ambos países elaboraran proyectos para promover la llegada de trabajadores japoneses a nuestro país. En México, algunas navieras buscaban obtener concesiones gubernamentales a cambio de traer colonos japoneses; en Japón, se fundaron agencias de emigración que se dedicaban a conseguir contratos para ciudadanos nipones en otros países (incluido México) y a gestionar el traslado y el establecimiento de esos trabajadores en los lugares de destino. Sin embargo, el flujo migratorio fue menos importante de lo que México esperaba debido a la falta de comunicaciones directas y a que los japoneses preferían migrar a Estados Unidos de América (EUA) y algunos otros países que ofrecían mejores oportunidades. ${ }^{31}$

De esta manera, según la bibliografía revisada, la llegada de japoneses se dio por dos vías: la colonización y el arribo de "braceros" o trabajadores contratados. En cuanto a la primera vía, el proyecto principal fue el establecimiento de una colonia nipona en Escuintla, Chiapas, para el cultivo del café y otros productos, la cual no prosperó por diversos motivos, aunque dio origen a una importante empresa binacional: la Sociedad Cooperativa Japonesa-mexicana. En cuanto a la segunda vía, la mayoría de los braceros llegaron a México con la intermediación de las agencias de emigración para trabajar en los sectores ferrocarrilero, minero y agrícola. Sin embargo, muchos de ellos transmigraban a EuA debido a las malas condiciones laborales mexicanas. ${ }^{32}$

Ahora bien, María Elena Ota Mishima se ha especializado en el estudio de la migración japonesa a México desde finales del siglo XIX hasta principios del siglo Xx. Sus obras principales son: México y Japón en el siglo XIX: La política exterior de México y la consolidación de la soberanía japonesa y Siete migraciones japonesas a México, 1890-1978. No obstante, en "Características sociales de los migrantes japoneses en México" expone sus hallazgos más importantes sobre la migración japonesa durante el porfiriato de manera sucinta y con datos más actualizados. En este último texto, la autora construye el perfil del migrante japonés promedio y brinda cifras sectoriales sobre la cantidad de nipones que México recibió durante el porfiriato.

En ese sentido, Ota Mishima asegura que alrededor de diez mil braceros japoneses arribaron a México entre 1900 y 1910. La mayoría de estos migrantes llegó a territorio mexicano para laborar en la en la construcción de vías férreas, en haciendas cañeras y en minas. En general, se trataba de trabajadores poco calificados de sexo masculino, solteros y jóvenes. Muchos se fueron a Estados Unidos, pero muchos otros permanecieron en México y echaron raíces, por lo que empezaron a formar una comunidad mexicano-japonesa, la cual fue creciendo durante el siglo xx hasta alcanzar su importancia actual. ${ }^{33}$

Por su parte, Moisés González Navarro considera que uno de los factores principales por los que la élite mexicana valoraba positivamente la llegada de migrantes japoneses era su semejanza racial con los indígenas (ojos rasgados, baja

31 Idem.

32 Idem.

33 OтA Mishima, María Elena, “Características sociales”, 1997, pp. 55-84. 
estatura, color de piel, pelo oscuro, etc.), la cual contribuiría a su rápida adaptación a las condiciones geográficas y climáticas del país. Otros autores exponen brevemente este argumento como una cuestión anecdótica, pero González Navarro asegura que el parecido físico entre nipones e indios era una de las razones principales por las que se creía que los trabajadores de esa nacionalidad podrían ser aptos para laborar en México. Esto es un buen ejemplo para ilustrar cómo el pensamiento racionalista estaba bien presente en nuestro país. ${ }^{34}$

Finalmente, Héctor Palacios profundiza en los factores que empujaban a los jóvenes japoneses a buscar nuevas oportunidades en países como México más allá de las políticas de emigración que el Estado nipón puso en marcha como válvula de escape para la presión demográfica. El autor asegura que hubo tres elementos principales que incentivaron a miles de japoneses a dejar su patria: la reforma fiscal, el servicio militar obligatorio y las guerras. ${ }^{35}$

La reforma fiscal abolió el viejo sistema de tributos pagados en especie e instauró impuestos personales pagados en efectivo, lo cual afectó severamente a miles de campesinos que se vieron orillados a buscarse la vida en el exterior. Muchos jóvenes también huían del servicio militar obligatorio recientemente impuesto, pues éste tenía una duración de tres años y había altas probabilidades de participar en algún conflicto bélico considerando el nuevo militarismo nipón. Otros migrantes eran soldados que habían combatido en las guerras sino-japonesa y ruso-japonesa; pero, al regresar a su país natal, no habían encontrado oportunidades laborales. ${ }^{36}$

Otro elemento valioso del texto de Palacios es que analiza la llegada de migrantes japoneses a Guadalajara durante el porfiriato. El autor considera que se ha estudiado mucho la colonia de Escuintla, Chiapas, y otros pocos flujos migratorios nipones a ciertas zonas del país, pero asegura que es necesario examinar este fenómeno en otros puntos de la geografía nacional, como Guadalajara, pues la inmigración japonesa se extendió a todo el territorio mexicano y, en cada región, el proceso se gestó de manera particular, por lo que sería recomendable hacer nuevos estudios que resalten las especificidades locales del fenómeno. ${ }^{37}$

\section{LA INCIDENCIA DE EUA}

Como se mencionó, muchos textos establecen que EUA influyó de distintas maneras en la relación México-Japón. Incluso, Enrique Cortés apunta que, desde un principio, cuando se firmó el Tratado, Japón no tenía intenciones de abrir un gran canal de comercio con México, pues consideraba que nuestro país estaba dentro de la esfera económica estadounidense y quería evitar cualquier tipo de problema con Washington. Así, según este autor, la Unión Americana fue un factor importante para el desarrollo de los vínculos bilaterales desde que éstos se establecieron. $^{38}$

34 González Navarro, Moisés, Los extranjeros en México, vol. 2, 1994, pp. 163-185.

35 Palacios, Héctor, “Japón y México”, 2012, pp. 105-140.

36 Idem.

37 Idem.

38 Cortés, Enrique, Relaciones entre México, 1980, p. 63. 
Además, como se aclaró en la sección anterior, muchos de los trabajadores nipones que llegaban a México transmigraban a EUA Según varios autores, este flujo de personas causó descontento en Washington, pues la xenofobia y el racismo en contra de chinos y japoneses estaban en auge en varias regiones estadounidenses. Así, en 1907, Japón firmó el Pacto de Caballeros con Estados Unidos, un acuerdo para limitar la migración japonesa no sólo al país de las barras y las estrellas, sino también a sus naciones vecinas: Canadá y México. ${ }^{39}$

Los estudiosos afirman que este tratado es una de las muestras más claras de cómo la Unión Americana tenía una incidencia muy grande en la relación bilateral, pues, en efecto, el Pacto redujo significativamente la migración nipona a México. ${ }^{40}$ De hecho, según Héctor Palacios, la discriminación hacia los japoneses en Estados Unidos fue tal, que la mayoría de los migrantes nipones que llegaron después de 1907 provenían de nuestro vecino del norte, ya que huían del racismo imperante en aquel país. ${ }^{41}$

Pero, según la literatura consultada, la atención que EUA le brindaba a la evolución de la relación México-Japón respondía a la desconfianza de Washington, que veía al Imperio nipón como adversario, a la luz de la lógica imperialista y expansionista con la que se manejaban las relaciones internacionales de principios del siglo Xx. Además, EUA visualizaba a Japón como un rival directo en la pugna por la hegemonía del Pacífico, por lo que consideraba peligroso y desafiante que estrechara lazos con México, su vecino sureño. Estos temores se agravaron con la victoria nipona en la guerra ruso-japonesa de $1905 .{ }^{42}$

De acuerdo con Paolo Riguzzi y Bertha Ulloa, el recelo de Washington hacia la relación bilateral se agravó especialmente con una serie de rumores que la prensa sensacionalista estadounidense difundió. En 1907, los diarios americanos crearon especial revuelo cuando México decidió no renovar el contrato de arrendamiento de una zona de Bahía Magdalena que la marina estadounidense utilizaba para llevar a cabo ejercicios y ensayos militares. ${ }^{43}$

Según los periodistas estadounidenses, el gobierno porfirista no había renovado el acuerdo debido a que firmaría un convenio con Japón para que las fuerzas armadas niponas se establecieran en esa bahía. Este rumor causó aún más temor y obtuvo mayor credibilidad cuando, por una desafortunada casualidad, un buqueescuela de la marina japonesa llegó a las costas mexicanas en las mismas fechas y las autoridades nacionales recibieron con toda cortesía a los oficiales de este barco. Incluso, había rumores periodísticos acerca de la supuesta negociación de un tratado secreto entre México y Japón para atacar conjuntamente a EUA y se

39 León Manríquez, José Luis y Tizili Apango, Eduardo, "México y Asia”, 2015, pp. 113-139; Palacios, Héctor, “Japón y México", 2012, pp. 105-140; CORTÉs, Enrique, Relaciones entre México, 1980, pp. 84-103; LaJous, Roberta, La política exterior, 2010, pp. 109-145; Haro, Francisco Javier; León, José Luis y Ramírez, Juan José, “Japón y los contornos”, 2011, p. 122; y Palacios, Héctor, “Japón y México”, 2012, pp. 105-140. Idem.

41 Palacios, Héctor, “Japón y México", 2012, pp. 105-140.

42 Lajous, Roberta, La política exterior, 2010, pp. 109-145; CoRTÉs, Enrique, Relaciones entre México, 1980, pp. 84-103; y Almada, Carlos, México y Japón, 2018, pp. 27-68.

43 UlloA, Bertha, "El juego de las potencias", 2010, pp. 51-66 y Riguzzi, Paolo, "México, Estados Unidos", 1992, pp. 365-436. 
decía que Japón quería fortalecer su presencia en México para asaltar el Canal de Panamá desde ahí. ${ }^{44}$

Llama la atención que Ulloa y Riguzzi fijen su atención en estos rumores, pues ninguno de sus textos versa específicamente sobre la relación México-Japón. Más bien, se centran en un panorama amplio de las relaciones exteriores del México porfirista y en los intereses que las grandes potencias de esa época tenían en nuestro país, lo cual demuestra que el acercamiento mexicano-japonés no era un tema menor, sino que era una cuestión que preocupaba genuinamente a Washington. Tan es así que Roberta Lajous cita a un congresista estadounidense que declaró: "A Díaz le costó la presidencia andar coqueteando con Japón". La autora reconoce que es una afirmación exagerada, pero asegura que, en efecto, el gobierno americano seguía con disgusto y preocupación la cordial relación de su vecino del sur con el imperio nipón. ${ }^{45}$

\section{NUEVOS ENFOQUES}

Tras esta revisión historiográfica, es momento de proponer algunos enfoques desde los que se podría tratar el tema en futuras investigaciones. En primer lugar, la mayoría de los autores concuerda en cuanto a que el Tratado de 1888 no dio los frutos materiales que se esperaban, pues el intercambio de bienes y capitales no creció sustancialmente tras su firma. Sin embargo, en general, se esgrimen explicaciones verosímiles, pero poco profundas, sobre el porqué de los magros resultados. En ese sentido, me parece que es necesario realizar estudios que analicen más a fondo cuáles fueron las razones por las que la relación económica no prosperó durante el porfiriato.

A continuación, se plantean algunas preguntas que podrían motivar estos ejercicios analíticos. ¿El tratado no dio dividendos materiales porque la influencia estadounidense no permitió una mayor presencia japonesa en México? ¿La falta de vías directas de comunicación explica este fracaso? De ser así, ¿por qué no prosperaron los diversos proyectos para establecer rutas marítimas directas y frecuentes? Finalmente, ¿cuál podía ser el interés de una nación que seguía en pleno proceso de desarrollo industrial, pero que estaba lejos de consolidar su industria, como era el caso de Japón, en exportar sus productos hacia México, un país con un mercado pequeño en comparación con los europeos y el estadounidense?

Por otro lado, la literatura mexicana acerca del tema propone que el Tratado de 1888 fue un parteaguas para Japón, pues le otorgó el precedente que necesitaba para poder renegociar los acuerdos desiguales con las potencias occidentales. Esta valoración parece verosímil y lógica, pero, al menos de este lado del Pacífico, hacen falta ejemplos que la fundamenten. Es decir, los autores caracterizan al Tratado como un instrumento valioso del que Japón se valió en las negociaciones para echar por tierra las condiciones inequitativas presentes en los acuerdos que tenía con los países europeos y EUA, pero no ejemplifican cómo fue que los

44 Idem

45 Lajous, Roberta, La politica exterior, 2010, p. 143. 
nipones utilizaron ese pacto como parte de su estrategia diplomática, ni cómo respondió Occidente ante esta táctica.

Asimismo, hacen falta estudios de carácter global sobre el tema. Es cierto que varios autores han tratado la relación México-Japón como parte de la estrategia porfirista de diversificación de los vínculos con el exterior, pero sería provechoso que futuras investigaciones explicaran esta alianza desde una perspectiva global. Propongo una primera veta para hacerlo. A finales del siglo XIX y principios del xx, Japón y México eran considerados como naciones poco civilizadas, aunque, al mismo tiempo, tenían cierta influencia regional y estaban sumergidas en un proceso de modernización. En ese sentido, sería interesante estudiar cuáles eran las motivaciones de dos países así para unirse en un contexto internacional caracterizado por la carrera imperialista, que estaba dominado por Europa y EUA. En otras palabras, más allá de la afinidad y la empatía que tenían ambos países por haber vivido experiencias históricas similares, ¿qué factores internos y, sobre todo, qué elementos del sistema internacional los incentivaron a acercarse?

Adicionalmente, me llama la atención que las negociaciones previas a la firma del Tratado de 1888 se llevaron a cabo en Washington y que el gobierno estadounidense le dio su visto bueno a Matías Romero para que estableciera un acuerdo sobre bases igualitarias con los nipones; pero, poco después, la Unión Americana veía con recelo y hasta con temor la relación México-Japón. Por eso, sería interesante analizar las razones por las que Estados Unidos empezó a preocuparse por una relación diplomática que, en un principio, había avalado. Si bien es claro que el expansionismo nipón y la carrera por la hegemonía del Pacífico desempeñaron un papel fundamental en este punto, aún no se han desarrollado los factores internos mexicanos que podrían haber causado desconfianza en la Casa Blanca.

Finalmente, en cuanto a la cuestión de la migración, no me queda más que reiterar la recomendación de Héctor Palacios: hace falta estudiar los flujos de trabajadores japoneses que estuvieron en México a escala local y no sólo nacional, pues en cada punto geográfico el proceso migratorio se vivió con sus propias especificidades y particularidades. También sería provechoso complementar los estudios de María Elena Ota Mishima y rastrear los sectores de la comunidad japonesa-mexicana que están en nuestro país desde el porfiriato.

\section{REFLEXIONES FINALES}

Después de esta revisión historiográfica, se puede concluir que hay varios consensos respecto a la relación México-Japón durante el porfiriato. De hecho, en general, las visiones de los distintos autores sobre los temas relacionados con esta cuestión son bastante similares y hay pocas interpretaciones que escapan a los puntos de acuerdo. En ese sentido, es importante destacar a Enrique Cortés, pues su libro Relaciones entre México y Japón durante el porfiriato es quizá el texto más citado por el resto de los autores que han trabajado el tema. Que la obra se 
haya escrito en 1980 y que permanezca como una de las más referenciadas nos da una idea de cómo las interpretaciones de los autores sobre el tema aquí tratado han cambiado poco en los últimos años. Con esta idea en mente, en la sección anterior, se plantearon algunas posibilidades para construir nuevos enfoques analíticos.

Otra obra básica para estudiar la relación México-Japón durante el porfiriato es México y Japón: a 130 años de relaciones diplomáticas de Carlos Almada. Este libro salió a la luz en 2018 como parte de los actos conmemorativos del establecimiento de los vínculos diplomáticos, por lo que es la publicación más reciente sobre el tema. Además, puesto que el embajador Almada estuvo adscrito en Japón, tuvo acceso a fuentes mexicanas y niponas - tanto primarias como secundarias-, lo cual contribuye a que su estudio sea uno de los más completos.

Por su parte, en la vertiente migratoria del tema, sin duda, María Elena Ota Mishima sigue siendo la máxima autoridad. No obstante, se trata de un caso similar al de Cortés: por supuesto que las aportaciones de la autora son muy valiosas y, en su momento, fueron grandes descubrimientos, pero sus obras más recientes se publicaron en la década de 1990, lo que da pie a la necesidad de que se aborde el tema desde nuevas aristas.

Ahora bien, es momento de reflexionar sobre el carácter "especial" de la relación bilateral con base en el balance historiográfico aquí expuesto. Sin embargo, antes de entrar en materia, es importante subrayar que, como cualquier otro adjetivo, la categorización "especial" es subjetiva. Por tanto, una cosa o un tema es especial o no dependiendo de a quién se le pregunte. De este modo, los siguientes párrafos dan cuenta de una opinión que, si bien está fundamentada en un ejercicio analítico realizado a partir de las ideas de los autores que se consultaron, sigue siendo un punto de vista personal carente de objetividad.

Una vez que realicé este balance y que repensé las referencias que los funcionarios mexicanos hacen sobre el carácter especial de la relación bilateral en los encuentros diplomáticos con Japón, considero que, en efecto, tienen algo de razón, pues los vínculos mexicano-japoneses poseen una dimensión histórica importante $y$, desde su origen, se caracterizaron por el buen entendimiento de ambos países. Cuentan con una dimensión histórica importante en cuanto a que los procesos históricos similares - y, hasta cierto punto, compartidos - permitieron la empatía y la comprensión mutua. En ese sentido, el entendimiento se dio desde un principio sobre la base de estas experiencias en común, pero también se fundamentó en la afinidad cultural y la cortesía diplomática que caracterizó a la política exterior de ambas naciones.

Otro factor que abona al carácter especial de esta relación bilateral es que, durante el porfiriato, los lazos comerciales, los flujos de inversión y el intercambio de capitales fue moderado y generó dividendos modestos, lo que me hace pensar que, en realidad, la relación se cimentó sobre algo más que bases económicas. Claro que, en la actualidad, la parte más importante de la agenda bilateral se relaciona con temas económicos y diplomáticos, pero no se limita a ellos. Va más allá. 
Hay un intenso intercambio académico de profesores, estudiantes e investigadores en ambos sentidos. Hay cooperación en diversas áreas, como los mecanismos de reacción ante los sismos y otros desastres naturales; incluso, Japón fue uno de los primeros países en prestar ayuda para la población mexicana afectada por los terremotos de septiembre de 2017 y no se limitó a remitir víveres, dinero y medicinas, sino que también envió uno de los equipos de rescate más numerosos y especializados. Hay una importante comunidad japonesa en México - conformada por migrantes recientes y también por personas de doble nacionalidad - que ha enriquecido nuestro panorama cultural, pues ha traído elementos japoneses y los ha adaptado a las costumbres y tradiciones mexicanas. Hay prestigiosas instituciones deportivas y educativas, como el Liceo Japonés y el Club Japonés, que muestran que la presencia nipona en nuestro país va más allá de lo económico.

Estos elementos se empezaron a construir desde que se establecieron los vínculos diplomáticos; es decir, precedieron a los grandes flujos de comercio e inversión. Por todo eso - la significación histórica de la relación bilateral, el entendimiento muto desde la negociación del Tratado de 1888, la cordialidad diplomática desde los tiempos de Díaz, la buena adaptación de la numerosa comunidad japonesa en México, etcétera-, se puede concluir que, efectivamente, se trata de una relación especial.

\section{BIBLIOGRAFÍA}

Almada, Carlos, México y Japón: a 130 años de relaciones diplomáticas, México, Secretaría de Relaciones Exteriores, 2018, pp. 27-68.

ARanda Ávila, Joel, "Revisión histórica de la participación de México en AsiaPacífico (1530-1889)", Universópolis: Revista estudiantil de Relaciones Internacionales, año 0, núm. 1, enero-junio 2012, pp. 59-78.

ConTés, Enrique, Relaciones entre México y Japón durante el porfiriato, México, Secretaría de Relaciones Exteriores, 1980.

González Navarro, Moisés, Los extranjeros en México y los mexicanos en el extranjero, México, El Colegio de México, 1994, vol. 2, pp. 163-185.

Haro, Francisco Javier; León, José Luis y Ramírez, Juan José, “Japón y los contornos de un sueño diversificador: entre Meiji y la posrevolución mexicana" en Mercedes de Vega (coord.), Historia de las relaciones internacionales de México, 1821-2010, México, Secretaría de Relaciones Exteriores, vol. 6 (Asia), 2011, pp. 117-134.

Kunimoto, Iyo, "La negociación del Tratado de Amistad, Comercio y Navegación de 1888 y su significado histórico", Revista mexicana de política exterior, vol. 83, núm. 91, 2008, pp. 91-100.

Lajous, Roberta, "El porfiriato" en Historia Mínima de las relaciones exteriores de México (1821-2000), México, El Colegio de México, 2012, pp. 116-143. Lajous, Roberta, La política exterior del porfiriato, México, El Colegio de México, 2010. 
León ManríQuez, José Luis y Tizili APAngo, Eduardo, "México y Asia Pacífico: proximidades y distancias de una dilatada relación", Revista CIDOB d'Afers Internacionals, núm. 110, septiembre 2015, pp. 113-139.

OтA Mishima, María Elena, "Características sociales de los migrantes japoneses en México" en Ota Mishima, María Elena (coord.), Destino México. Un estudio de las migraciones asiáticas a México, siglo XIX y XX, México, El Colegio de México, 1997, pp. 55-84.

Ota Mishima, María Elena, México y Japón en el siglo XIX: La política exterior de México y la consolidación de la soberanía japonesa, México, Secretaría de Relaciones Exteriores, 1976.

Palacios, Héctor, "Japón y México: el inicio de sus relaciones y la inmigración japonesa durante el Porfiriato", México y la Cuenca del Pacífico, núm. 1, mayo-agosto 2012, pp. 105-140.

Riguzzi, Paolo, "México, Estados Unidos y Gran Bretaña, 1867-1910: una difícil relación triangular", Historia Mexicana, vol. 41, núm. 3, 1992, pp. 365-436. RODRÍGUEz HUERTA, Gabriela, "Recorrido histórico por la política exterior mexicana" en México en el mundo, Constitución y política exterior, México, Fondo de Cultura Económica, 2017, pp. 87-104.

UlloA, Bertha, "El juego de las potencias" en La lucha revolucionaria, México, El Colegio de México, 2010, pp. 51-66.

Esta obra está bajo licencia internacional Creative Commons ReconocimientoNo-Comercial-CompartirIgual 4.0.

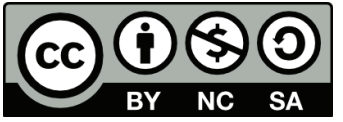

